University of Texas at El Paso

ScholarWorks@UTEP

$10-2013$

\title{
Studying Volatility and Dependency of Chinese Outbound Tourism Demand in Singapore, Malaysia, and Thailand: A Vine Copula Approach
}

Jianxu Liu

Chiang Mai University, liujianxu1984@163.com

Songsak Sriboonchitta

Chiang Mai University, songsakecon@gmail.com

Hung T. Nguyen

New Mexico State University - Main Campus, hunguyen@nmsu.edu

Vladik Kreinovich

The University of Texas at El Paso, vladik@utep.edu

Follow this and additional works at: https://scholarworks.utep.edu/cs_techrep

Part of the Computer Sciences Commons

Comments:

Technical Report: UTEP-CS-13-65

Published in: Van-Nam Huynh, Vladik Kreinovich, and Songsak Sriboonchitta (eds.), Modeling

Dependence in Econometrics, Springer Verlag, Berlin, Heidelberg, 2014, pp. 255-272.

\section{Recommended Citation}

Liu, Jianxu; Sriboonchitta, Songsak; Nguyen, Hung T.; and Kreinovich, Vladik, "Studying Volatility and Dependency of Chinese Outbound Tourism Demand in Singapore, Malaysia, and Thailand: A Vine Copula Approach" (2013). Departmental Technical Reports (CS). 810.

https://scholarworks.utep.edu/cs_techrep/810

This Article is brought to you for free and open access by the Computer Science at ScholarWorks@UTEP. It has been accepted for inclusion in Departmental Technical Reports (CS) by an authorized administrator of ScholarWorks@UTEP. For more information, please contact Iweber@utep.edu. 


\title{
Studying Volatility and Dependency of Chinese Outbound Tourism Demand in Singapore, Malaysia, and Thailand: A Vine Copula Approach
}

Jianxu Liu, Songsak Sriboonchitta, Hung T. Nguyen and Vladik Kreinovich

\begin{abstract}
This paper investigates the volatility and dependence of Chinese tourism demand for Singapore, Malaysia, and Thailand (SMT) destinations, using the vine copula based auto regression moving average-generalized autoregressive conditional heteroskedasticity (ARMA-GARCH) model. It is found that a jolt to the tourist flow can have long-standing ramifications for the SMT countries. The estimation of the vine copulas among SMT show that the Survival Gumbel, Frank, and Gaussian copulas are the best copulas for Canonical vine (C-vine) or Drawable vine (D-vine) among the possible pair-copulas. In addition, this paper illustrates the making of time-varying Frank copulas for vine copulas. Finally, there is a discussion on tourism policy planning for better managing the tourism demand for the SMT countries. We suggest tour operators and national tourism promotion authorities of SMT collaborate closely in the marketing and promotion of joint tourism products.
\end{abstract}

\footnotetext{
Jianxu Liu

Faculty of Economics, Chiang Mai University, Chiang Mai 50200 Thailand

e-mail: liujianxu1984@163.com

Songsak Sriboonchitta

Faculty of Economics, Chiang Mai University, Chiang Mai 50200 Thailand

e-mail: songsakecon@gmail. com

Hung T. Nguyen

Department of Mathematical Sciences, New Mexico State University, New Mexico, USA

e-mail: hunguyenenmsu.edu

Vladik Kreinovich

Computer Science Department, University of Texas at El Paso, Texas, USA

e-mail: vladik@utep.edu
} 


\section{Introduction}

Outbound tourism in China is growing rapidly, and has become a significant contributor to international tourism. In 2011, the total volume of the outbound tourists made more than 70 million trips, with an increase by $22.4 \%$ year by year. By 2015 , the China National Tourism Administration (CNTA) forecasts, the Chinese international passengers will increase to 100 million, a quantity that will put China in the numero uno position in the international tourism source market.

With the immense increase in Chinese outbound tourism, the number of Chinese visitors and their expenditure has become the most important and the most potential passengers' market. As one of their classic, routine travel destinations, SMT (Singapore, Malaysia, and Thailand), which is a very popular tourist destination for the Chinese tourists, is witnessing more changes shining through. For example, China has become the second largest passenger source country for Singapore, only behind Indonesia, in 2011; China is Malaysia's third largest source of tourists, following Indonesia and Singapore, and in the first half of 2012, 871,959 Chinese tourists visited Malaysia, up 53.4\% year by year; for Thailand, The Tourism Authority of Thailand (TAT) forecasts that China will become their largest passenger source market in 2014. In addition, it is easy to see, as shown in Figure 1, that the outbound tourism to Singapore, Malaysia, and Thailand maintains the overall upward trend and reaches peaks and troughs simultaneously. In view of this scenario, we infer that the volatilities of the outbound tourism to Singapore, Malaysia, and Thailand may be similar to each other, as well, and that their dependence should be also quite high.

The tourism industries in Singapore, Malaysia, and Thailand possess their own prominent places. First, the total contribution of Travel and Tourism to the GDP of these countries (SMT) accounts for $10.6 \%, 15.8 \%$, and $16.3 \%$, respectively, of their total GDP, in 2011. Second, the total contribution of Travel and Tourism to the employment sector was 266,500 jobs (8.6\% of total employment) for Singapore, 1,587,000 jobs (13.8\% of total employment) for Malaysia, and 4,468,500 jobs for Thailand (11.4\% of total employment), in 2011. Third, in 2011, Singapore, Malaysia, and Thailand generated SGD 22.5 bn (3.3\% of total exports), MYR 62.4 bn (8.4\% of total exports) and THB 950.4 bn (11.4\% of total exports) from visitor exports. It is thus clear that it is the tourism industry of Singapore, Malaysia, and Thailand that drives the development of the whole economy and the society of these countries.

It is worth mentioning, besides, that the volume of China outbound tourism is enormous; the great spending power ranked No. 2 (USD 59.52 bn) in the world in 2011. SMT may benefit from analyzing the international tourism demands from China. Hence, the analysis of volatility and dependence of tourism demand is essential for investigating the effects of shocks and co-movements in the SMT tourism demand from China. Furthermore, for tourism managers and travel corporations, it is important to evaluate the dependence structure of tourism demand and to discern attractive opportunities. They also need to figure out the implied threat caused 


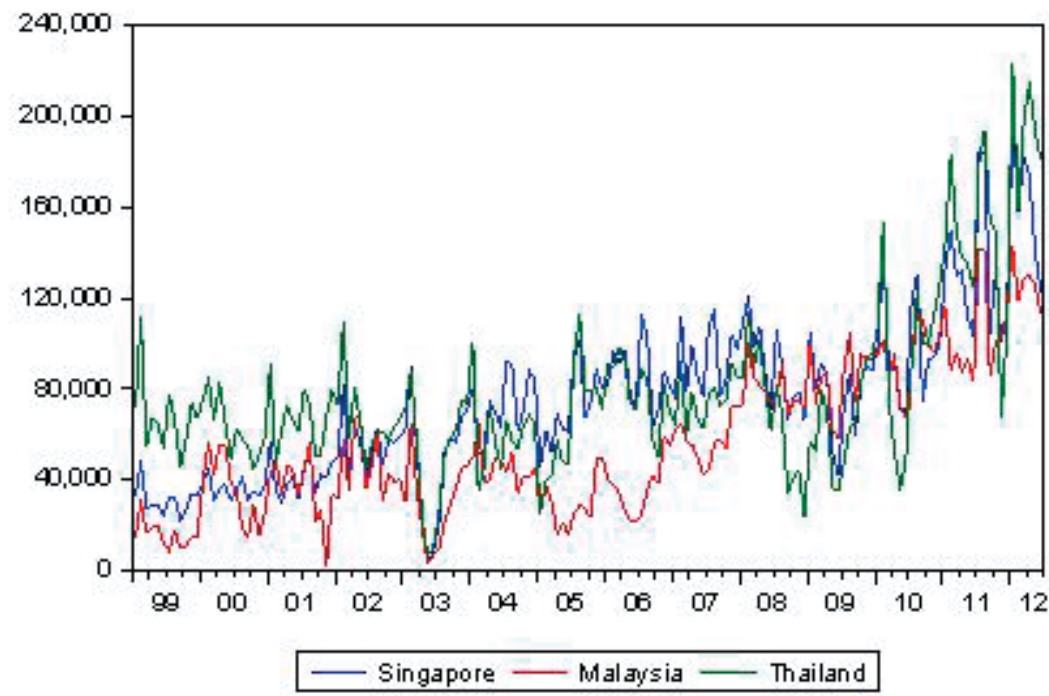

Fig. 1 Tourist flows to SMT from China.

by volatilities in tourism demand. Mastering the behaviors of volatility and dependence structure can help governments and tourism corporations adjust strategies for improving the profitability of the tourism industry and reducing adverse impacts such as political unrest, natural disaster, etc.

This study is organized as follows. Section 2 reviews the tourism research, the copula based GARCH model, and the vine copulas. The copula based ARMAGARCH model is discussed in section 3 which includes ARMA-GARCH models for margins, copulas, and vines. Data description and empirical findings are presented in section 4. Policy planning is discussed in section 5, while some concluding remarks are given in section 6 .

\section{Literature review}

Recognizing the relevance and significance of tourism industry to SMT economy, a number of studies have been undertaken on various aspects of outbound tourism from China to SMT: for example, Li et al. [1] examined the Chinese tourists' expectations of outbound travel products, Lee [22] studied the dynamic interactions be- 
tween hotel room rates and international inbound tourists in Singapore, and Chang et al. [5] forecasted tourism demand from East Asia to Thailand. However, none of the literature relates to the dependencies and volatility of tourism demand from China to SMT except just one paper which is by Liu and Sriboonchitta [15] who studied the volatility and dependence between tourist arrivals from China to Thailand and those to Singapore. It was found that the Gaussian copula fitted very well, and that the Kendall's tau was 0.5737. It is thus clear that the dependence of Chinese outbound tourism demand between the destinations of Singapore and Thailand is very high.

Many scholars studied tourism demand by applying econometric and statistical tools to analyze the volatilities and relationships of inbound or outbound tourism demand. Kim and Wong [5], and Song et al. [6] used the univariate autoregressive conditional heteroskedasticity (GARCH) model to analyze the volatility of tourism demand. Chan et al. [6] used the symmetric constant conditional correlation-multivariate generalized autoregressive conditional heteroskedasticity (CCC-MGARCH) model and the symmetric vector ARMA-GARCH to model the multivariate international tourism demand and volatility among the four tourism source countries to Australia. Hoti et al. [15] made use of the VARMA-GARCH model to investigate international tourism and country risk spillovers for Cyprus and Malta. Seo et al. [9] analyzed the relationships of the Korean outbound tourism demand by using the MGARCH and Vector Error Correction (VEC) models. Lee [22] investigated the short-run and the long-run dynamic interactions using the cointegration and Granger causality test.

However, the above-mentioned papers always assumed the conditional correlation to be the linear Pearson's correlation and constant over time, which is a strong and strict assumption. Of late, the copula-GARCH model has been very popular in the financial field, as it can be used to analyze the volatilities and dependence structure. Patton [11] used this model to analyze the dynamic dependence between the exchange rates of YenUSD and DMUSD. Jondeau and Rockinger [13] assumed the marginals of the copula-GARCH model to be a skewed student-t distribution in order to capture heavy tail information regarding the international stock market. Lee and Long [12] proposed copula based multivariate GARCH model with uncorrelated dependent errors, which are generated through a linear combination of dependent random variables. Wu [13] also researched the economic value of co-movement between oil prices and exchange rates using copula-based GARCH models. Wang et al. [8] studied the dynamic dependence between the Chinese market and other international stock markets using the time-varying copula approach. But the above-mentioned studies all used the bivariate copula-GARCH model to study the dependence structure.

To study the multivariate dependence structure, Joe [29] gave the first paircopula construction (PCC) of a multivariate copula, the construction of which is dependent on distribution functions. Bedford and Cooke [19] [8] expressed these constructions in terms of densities, and organized these constructions in a graphical way involving a sequence of nested trees, which are called regular vines. They also proposed two subclasses of PCC, which we call the C-vine and D-vine cop- 
ulas. Note that the C-vine and D-vine copulas have been widely used in finance asset returns and other data by many researchers, such as Aas et al. [23], Min and Czado [19], and Czado [8]. For studying the dependence of outbound tourism demand in the three countries (SMT), we make use of the C-vine and D-vine copulas instead of the bivariate copula in the copula-GARCH model. In other words, we use the ARMA-GARCH model to fit the marginals, and then transform the standardized residuals into specified distributions; finally, we make use of the C-vine and D-vine copulas to capture the dependence structure.

To sum up, the main contributions of this study are as follows: (1) we introduce the $\mathrm{C}$-vine and D-vine copula based ARMA-GARCH model into tourism demand research; (2) we propose time-varying Frank copula to capture the dynamic Kendall's tau for vine copulas; (3) we investigate the impact of the short-run and long-run Chinese outbound tourism demand for SMT; (4) we compare the results of the bivariate copulas with those of the vine copulas, thus finding out the dominant country among SMT; and (5) finally, through this study, we provide inferences that are applicable for competitive destination strategies and policy development.

\section{Copula based ARMA-GARCH model}

This paper utilizes copula based ARMA-GARCH model to analyze the volatility and dependence of Chinese outbound tourism demand to SMT destinations. We filter growth rate data using the ARMA-GARCH model with appropriate distributions, for example, the skewed student-t, skewed GED, and skewed normal, and transform standardized residuals to copula data $\left(u_{1}=F_{1}\left(x_{1}\right), u_{2}=F_{2}\left(x_{2}\right)\right.$, and $\left.u_{3}=F_{3}\left(x_{3}\right)\right)$ by using appropriate distribution functions. After that, we estimate the bivariate copula and the $\mathrm{C}$-vine and $\mathrm{D}$-vine copulas using the maximum likelihood estimation method.

\subsection{ARMA-GARCH model for margins}

Bollerslev [22] proposed the GARCH (generalized autoregressive conditional heteroskedasticity) model, which has replaced the ARCH model in application and has since been widely used in econometrics, economics, etc. In accordance with the findings of Ling [24], the ARMA (p, q)-GARCH (k, l) model can be formed as 


$$
\begin{gathered}
r_{t}=c+\sum_{i=1}^{p} \phi_{i} r_{t-i}+\sum_{i=1}^{q} \psi_{i} \varepsilon_{t-i}+\varepsilon_{i} \\
\varepsilon_{t}=h_{t} \eta_{t} \\
h_{t}^{2}=\omega+\sum_{i=1}^{k} \alpha_{i} \varepsilon_{t-i}^{2}+\sum_{i=1}^{l} \beta_{i} h_{t-i}^{2}
\end{gathered}
$$

where $\sum_{i=1}^{p} \phi_{i}<1, \omega>0, \alpha_{i}>=0, \beta_{i}>=0, \sum_{i=1}^{k} \alpha_{i}+\sum_{i=1}^{l} \beta_{i}<1$, and the time series $r_{t}$ are return data; the formulas (1) and (3) are known as the conditional mean equation and conditional variance equation, respectively; the formula (2) shows that these return residuals are split into a stochastic piece $\eta_{t}$ and a time dependent standard deviation $h_{t}$. The values of $\alpha_{i}$ and $\beta_{i}$ indicate the presence or absence of short-run shock and persistence of volatility, respectively. If the value of $\alpha_{i}$ is larger, then the short-term unexpected factors affecting the volatility have greater influence. If the value of $\sum_{i=1}^{k} \alpha_{i}+\sum_{i=1}^{l} \beta_{i}$ is larger, then the impact of unexpected shock to volatility has the longer duration. $\eta_{t}$ is the standardized residual, which can be assumed for any distribution. In this study, we assume the distribution of the standardized residuals to be the skewed student-t distribution or skewed-generalized error distribution (GED), both of which can capture the characteristics of heavy tail and asymmetry, anyway. The standardized skewed-t and skewed-GED distributions can be expressed as

$$
\begin{gathered}
f_{\text {skt }}\left(x_{i} \mid v, \gamma\right)=\frac{2}{\left(\gamma+\gamma^{-1}\right)}\left\{f_{v}\left(x_{i} / \gamma\right) I_{[0, \infty]}\left(x_{i}\right)+f_{v}\left(\gamma x_{i}\right) I_{[\infty, 0]}\left(x_{i}\right)\right\} \\
f_{\text {sged }}\left(x_{i} \mid v, \gamma\right)=v(2 \theta \Gamma(1 / v))^{-1} \times \exp \left(-\frac{\left|x_{i}-\delta\right|^{v}}{\left(1-\operatorname{sign}\left(x_{i}-\delta\right) \gamma\right)^{v} \theta^{v}}\right)
\end{gathered}
$$

where

$$
\begin{gathered}
A=\Gamma(2 / v) \Gamma(1 / v)^{-0.5} \Gamma(3 / v)^{-0.5} \\
S(\gamma)=\sqrt{1+3 \gamma^{2}-4 A^{2} \gamma^{2}} \\
\delta=2 \gamma A \times S(\gamma)^{-1} \\
\theta=\Gamma(3 / v)^{-0.5} \sqrt{\Gamma(1 / v)} S(\gamma)^{-1}
\end{gathered}
$$

where $f_{v}($.$) is the density of the student t-distribution, the parameter v$ represents the number of degrees of freedom, $\gamma$ is the skewness parameter ranging from 0 to $\infty, I$ denotes the indicator function, and "sign" is the sign function. 


\subsection{Copulas}

Copulas [25] have long been recognized and developed in various fields like econometrics, economics, financials, etc. If $X=\left(X_{1}, X_{2}, \ldots, X_{n}\right)$ is a random vector with joint distribution function $\mathrm{H}$ and marginal distributions $F_{1}, F_{2}, \ldots, F_{n}$, then there exists a function $\mathrm{C}$ called copula, such that

$$
H\left(x_{1}, x_{2}, \ldots, x_{n}\right)=C\left(F_{1}\left(x_{1}\right), F_{2}\left(x_{2}\right), \ldots, F_{n}\left(x_{n}\right)\right)
$$

The copula $\mathrm{C}$ is extracted from the joint $\mathrm{H}$ and marginals $F_{1}, F_{2}, \ldots, F_{n}$ as

$$
C\left(u_{1}, u_{2}, \ldots, u_{n}\right)=H\left(F_{1}^{-1}\left(u_{1}\right), F_{2}^{-1}\left(u_{2}\right), \ldots, F_{n}^{-1}\left(u_{n}\right)\right)
$$

where $F_{i}^{-1}\left(u_{i}\right)=\inf \left\{x \in \mathfrak{R}: F_{i}(x) \geq u_{i}\right\}$. If $F_{i}$ is absolutely continuous and strictly increasing, then

$$
\begin{aligned}
f\left(x_{1}, x_{2}, \ldots, x_{n}\right) & =\frac{\partial H\left(x_{1}, x_{2}, \ldots, x_{n}\right)}{\partial x_{1} \cdots \partial x_{n}} \\
& =\frac{\partial C\left(u_{1}, u_{2}, \ldots, u_{n}\right)}{\partial u_{1} \cdots \partial u_{n}} \times \prod \frac{F\left(x_{i}\right)}{\partial x_{i}} \\
& =c\left(u_{1}, u_{2}, \ldots, u_{n}\right) \times \prod f_{i}\left(x_{i}\right)
\end{aligned}
$$

The joint distribution $\mathrm{H}$ contains all the statistical information about $X=\left(X_{1}, X_{2}\right.$, $\left.\ldots, X_{n}\right)$. In particular, the marginal distributions of the components are derived as

$$
F_{i}\left(x_{i}\right)=H\left(\infty, \infty, \cdots, x_{i}, \infty, \infty\right)
$$

In this study, the Gaussian copula, T copula, Clayton copula, Frank copula, Gumbel copula, Joe copula, BB1 copula, BB6 copula, BB7 copula, BB8 copula, and rotated copulas have been utilized to analyze the dependence structure (see Brechmann and Schepsmeier [15]).

\subsection{Vines}

A bivariate copula vine specification is called a pair-copula construction or a vine copula. Compared to some multivariate copulas, vine copulas are more flexible in the high dimensions. For example, multivariate normal copula does not have tail de- 
pendence; multivariate t-copula has only a single degree of freedom parameter and symmetric tail dependence. For three variables, we can assume that 12 is the first pair, then the second pair is either 13 or 23 , and the third pair should be $23 \mid 1$ or $13 \mid 2$. The structure $12,13,23 \mid 1$ is the standard form of Canonical vine copula (C-vines), and the other 12, 23,13|2 is called Drawable vine copula (D-vines).

To use the C-vine and D-vine constructions to represent dependency structure through copulas, we assume that there are three univariate marginals that are uniform in $[0,1]$. Note that these univariate marginals correspond to cumulative distribution functions of the standardized residuals by generating from ARMA-GARCH model. Here, we concentrate on the C-vine and D-vine representations with three variables. The densities of the $\mathrm{C}$-vine and $\mathrm{D}$-vine copulas can be expressed as

$c\left(u_{1}, u_{2}, u_{3}\right)=c_{12}\left(u_{1}, u_{2}\right) \cdot c_{13}\left(u_{1}, u_{3}\right) \cdot c_{23 \mid 1}\left(F\left(u_{2} \mid u_{1}\right), F\left(u_{3} \mid u_{1}\right)\right)$ for C-vine copula

and

$c\left(u_{1}, u_{2}, u_{3}\right)=c_{12}\left(u_{1}, u_{2}\right) \cdot c_{23}\left(u_{2}, u_{3}\right) \cdot c_{13 \mid 2}\left(F\left(u_{1} \mid u_{2}\right), F\left(u_{3} \mid u_{2}\right)\right)$ for D-vine copula

where

$$
\begin{aligned}
& F\left(u_{2} \mid u_{1}\right)=\frac{\partial C_{12}\left(u_{1}, u_{2}\right)}{\partial u_{1}} \\
& F\left(u_{3} \mid u_{1}\right)=\frac{\partial C_{13}\left(u_{1}, u_{3}\right)}{\partial u_{1}} \\
& F\left(u_{1} \mid u_{2}\right)=\frac{\partial C_{12}\left(u_{1}, u_{2}\right)}{\partial u_{2}} \\
& F\left(u_{3} \mid u_{2}\right)=\frac{\partial C_{23}\left(u_{2}, u_{3}\right)}{\partial u_{2}}
\end{aligned}
$$

There are two things need to be finished before we estimate vine copulas model. One is the selection of a specific ordering; the other is the choice of pair-copula families. In this study, we employ different methods to select the orderings of the variables in the $\mathrm{C}$-vine and $\mathrm{D}$-vine models. For the $\mathrm{C}$-vine model, we calculate the sum of the empirical Kendall's $S_{\tau}^{i}=\sum_{j=1, i \neq j}^{n} \tau_{i, j}$ (see Czado et al. [22]) for each variable $i$, and select the maximum one as the first variable. After that, we reorder the remaining variables and repeat the process of calculating the sum of Kendall's tau, thus finding out the second and third variables. For the D-vine model, we just determine the order that satisfies the maximization of the sum of the empirical Kendall's tau $S_{\tau}=\sum_{i=1}^{n-1} \tau_{i, i+1}$. To choose the appropriate pair-copula families, we firstly estimate all possible copula families for $C_{12}, C_{13}$ (C-vine), and for $C_{12}, C_{23}$ (D-vine) by using maximum likelihood method. Then, we determine the required observations 
for $C_{23 \mid 1}$ and $C_{13 \mid 2}$ through the formulas (16)-(19). Thus, both C-vine and D-vine copulas can be estimated, and the Akaike information criterion (AIC) and Bayesian information criterion (BIC) can be calculated as well. Thereby, the copula families corresponding to the minimum values of AIC and BIC are selected among many copula families.

To improve efficiency of estimation of vine copula models, we need consider two-step maximum likelihood estimation method (see Aas et al. [23], Czado et al. [22]). The purpose of the first step is to obtain the starting values of the appropriate copula families, thus this step has been implemented in calculating AIC and BIC process. In the last step, all parameters of C-vine and D-vine copulas are estimated by the full maximum likelihood. The corresponding log-likelihood can be constructed by using the formulas (10) and (11). The log-likelihood functions of $\mathrm{C}$-vine and $\mathrm{D}$-vine copulas can be written as

$$
\begin{aligned}
L_{C}\left(u_{1}, u_{2}, u_{3} ; \theta\right) & =\sum_{i=1}^{n}\left[\log c_{12}\left(u_{1, i}, u_{2, i} ; \theta_{1}\right)+\log c_{13}\left(u_{1, i}, u_{3, i} ; \theta_{2}\right)\right. \\
& \left.+\log c_{23 \mid 1}\left(F\left(u_{2, i} \mid u_{1, i}\right), F\left(u_{3, i} \mid u_{1, i} ; \theta_{3}\right)\right)\right]
\end{aligned}
$$

and

$$
\begin{aligned}
L_{D}\left(u_{1}, u_{2}, u_{3} ; \theta\right) & =\sum_{i=1}^{n}\left[\log c_{12}\left(u_{1, i}, u_{2, i} ; \theta_{1}\right)+\log c_{23}\left(u_{2, i}, u_{3, i} ; \theta_{2}\right)\right. \\
& \left.+\log c_{13 \mid 2}\left(F\left(u_{1, i} \mid u_{2, i}\right), F\left(u_{3, i} \mid u_{2, i} ; \theta_{3}\right)\right)\right]
\end{aligned}
$$

where $\theta$ is the parameter vector that need to be estimated; $\theta_{1}, \theta_{2}$ and $\theta_{3}$ represent the parameters corresponding to the appropriate copula families.

\section{Empirical results}

\subsection{Data}

This paper models the time series of the difference between the logarithms of the monthly international arrivals (from January 1999 to June 2012) from China to Singapore, Malaysia, and Thailand. The data description and statistics are shown in Table 1: all the mean values are positive, the skewness values of both Singapore and Thailand are negative, and the kurtosis values are greater than 3. It is thus clear that the data show non-normality and that the data of Singapore and Thailand are skewed to the left. The results of the Jarque-Bera test reject the null hypothesis that the data are from a normal distribution, which are more convictive explanations for non-normality distributions, thereby implying that the skewed distribution is the 
more appropriate one for our study.

Table 1 Data Description and Statistics

\begin{tabular}{llll}
\hline & Singapore & Malaysia & Thailand \\
\hline Mean & 0.007982 & 0.012729 & 0.005707 \\
Median & 0.040844 & 0.007487 & 0.008301 \\
Maximum & 0.923611 & 2.848938 & 0.897066 \\
Minimum & -1.750788 & -2.645770 & -1.281747 \\
Std. Dev. & 0.325849 & 0.466296 & 0.343930 \\
Skewness & -0.888538 & -0.020366 & -0.652907 \\
Kurtosis & 7.744626 & 16.98058 & 4.556646 \\
Jarque-Bera & 172.1994 & 1311.199 & 27.69398 \\
Probability & 0.000000 & 0.000000 & 0.000001 \\
\hline
\end{tabular}

\subsection{Estimation results of ARMA-GARCH model}

Table 2 presents the results of the ARMA-GARCH model with different assumptions of marginal distribution. To analyze the volatility of the China outbound tourist demand to STM, we employ ARMA $(12,4)-G A R C H ~(1,1)$ with skewed student$\mathrm{t}$ distribution for Singapore, ARMA $(6,6)$-GARCH $(1,1)$ with skewed student-t distribution for Malaysia, and ARMA $(12,4)-\operatorname{GARCH}(1,1)$ with skewed-GED distribution for Thailand. The values of the GARCH coefficient, or $\beta$, equal 0.5482, 0.8467 , and 0.6993 , and they are significant as well. These results indicate that a shock to the tourist arrival series has long-run persistence in all cases, and that Chinese tourists outbound to Malaysia have stronger long-run persistence. The estimated ARCH effect, or $\alpha$, is significant only to the tourist arrival series from China to Thailand, and so tourist arrivals from China to both Singapore and Malaysia do not have short-run persistence. The values of the parameter $\gamma$ equal $0.8862,0.9083$, and 0.6626 in each model of SMT, respectively, implying that the Chinese outbound tourism demand in SMT are skewed to the left, and the series of the destination Thailand is more skewed to the left.

Since the parameters $\gamma$ and $v$ are significant, we transform the standardized residuals into standard skewed student-t distribution and skewed-GED distribution as margins. However, the margins must satisfy the condition of uniform distribution from 0 to 1 . If it cannot satisfy this condition, then the misspecified model for the marginal distribution may cause incorrect-fit copulas. Thus, testing for marginal 
distribution model misspecification is a critical step in constructing multivariate distribution models using copulas. Therefore, we present the Box-Ljung test for evaluating the serial independence of the marginals, $F_{s k t}\left(x_{\text {sing }, t}\right), F_{s k t}\left(x_{\text {malay }, t}\right)$, and $F_{\text {sged }}\left(x_{\text {thai, }}\right)$, and the Kolmogorov-Smirnov (K-S) test for the distribution specification. The results of the KS test and the Box-Ljung test are given in Table 3. It is very clear that each of the series accepts the null hypothesis, which means that all the three marginals are of uniform distribution. The second part of Table 3 shows the results of the Box-Ljung test, which evaluates the serial independence of the first four moments, and it can be observed that all of them accept the null hypothesis at the 0.10 level. Therefore, the marginals that we assumed satisfy the two preconditions: uniformity and serial independence.

\subsection{Estimation results of vine copulas}

For the C-vine copula, the order is Thailand, Malaysia, and Singapore, so we need to estimate $C\left(F_{\text {sged }}\left(x_{\text {thai }, t}\right), F_{\text {skt }}\left(x_{\text {malay }, t}\right)\right), C\left(F_{\text {sged }}\left(x_{\text {thai }, t}\right), F_{\text {skt }}\left(x_{\text {sing }, t}\right)\right)$, and $C\left(F_{\text {skt }}\left(x_{\text {malay }, t}\right), F_{\text {skt }}\left(x_{\text {sing }, t}\right) \mid F_{\text {sged }}\left(x_{\text {thai }, t}\right)\right)$. For the D-vine copula, the order is Singapore, Thailand, and Malaysia. As far as the structures of the C-vine and D-vine are concerned, the $\mathrm{D}$-vine has the same pair-copulas as the $\mathrm{C}$-vine. Therefore, in this case, we only need to do the calculation either for the $\mathrm{C}$-vine or for the $\mathrm{D}$-vine. Nevertheless, all the possible vine structures are calculated for a comprehensive analysis of the SMT inbound tourism from China.

The possible pair-copula families were the Gaussian copula, T copula, (Survival) Clayton copula, Frank copula, (Survival) Gumbel copula, (Survival) Joe copula, (Survival) BB1 copula, (Survival) BB6 copula, (Survival) BB7 copula, (Survival) BB8 copula, and rotated copulas. We make use of the AIC and BIC to choose the best copula for each pair. In Table 4, we present the results of the vine copulas and Kendall's tau for each best copula. The table shows that the Survival Gumbel, Frank, and Gaussian copulas are the best copulas for the C-vine or D-vine among the possible pair-copula families. First, we can find that China outbound tourism demand between Thailand and Malaysia has lower tail dependence equaling 0.2643 , implying that negative influences may have simultaneous impact on these two countries' tourism industries. Second, China outbound tourism demand between Thailand and Singapore shows stronger dependence equaling 0.5285 , but there does not exist tail dependence, which illustrates the fact that any positive and negative shocks cannot have an effect on these two countries' tourism industries at the same time. Third, the dependency parameter of the Gaussian copula between Singapore and Malaysia conditional on Thailand is not significant, which means that the inbound tourism demand of Singapore and Malaysia from China is independent, given the Thailand inbound tourism from China as condition, while the inbound tourism demand of 
Table 2 Results of ARMA-GARCH Model

\begin{tabular}{|c|c|c|c|c|c|}
\hline & Singapore & & Malaysia & & Thailand \\
\hline AR1 & $\begin{array}{l}0.6281 * * * \\
(6.771 \mathrm{e}-05)\end{array}$ & Constant & $\begin{array}{l}0.0198 * * * \\
(2.857 \mathrm{e}-05)\end{array}$ & AR1 & $\begin{array}{l}0.4041 * * * \\
(0.0024)\end{array}$ \\
\hline AR2 & $\begin{array}{l}0.4762 * * * \\
(6.802 \mathrm{e}-05)\end{array}$ & AR1 & $\begin{array}{l}0.0495^{* * *} \\
(5.772 \mathrm{e}-05)\end{array}$ & AR2 & $\begin{array}{l}0.6583 * * * \\
(0.0023)\end{array}$ \\
\hline AR3 & $\begin{array}{l}0.4621 * * * \\
(7.236 \mathrm{e}-05)\end{array}$ & AR2 & $\begin{array}{l}0.6758 * * * \\
(5.678 \mathrm{e}-05)\end{array}$ & AR3 & $\begin{array}{l}0.5453 * * * \\
(0.0039)\end{array}$ \\
\hline AR4 & $\begin{array}{l}1.2550 * * * \\
(6.808 \mathrm{e}-05)\end{array}$ & AR3 & $\begin{array}{l}0.2839 * * * \\
(5.774 \mathrm{e}-05)\end{array}$ & AR4 & $\begin{array}{l}0.1460 * * * \\
(0.0059)\end{array}$ \\
\hline AR5 & $\begin{array}{l}1.8250 * * * \\
(7.913 \mathrm{e}-05)\end{array}$ & AR4 & $\begin{array}{l}0.4870 * * * \\
(6.088 \mathrm{e}-05)\end{array}$ & AR5 & $\begin{array}{l}0.1723 * * * \\
(0.0025)\end{array}$ \\
\hline AR6 & $\begin{array}{l}0.0595 * * * \\
(6.816 \mathrm{e}-05)\end{array}$ & AR5 & $\begin{array}{l}0.8201 * * * \\
(6.284 \mathrm{e}-05)\end{array}$ & AR6 & $\begin{array}{l}0.0143 * * * \\
(0.0020)\end{array}$ \\
\hline AR7 & $\begin{array}{l}0.0231 * * * \\
(6.807 \mathrm{e}-05)\end{array}$ & AR6 & $\begin{array}{l}0.3124 * * * \\
(5.553 \mathrm{e}-05)\end{array}$ & AR7 & $\begin{array}{l}0.1865^{* * *} \\
(0.0018)\end{array}$ \\
\hline AR8 & $\begin{array}{l}0.0088 * * * \\
(1.230 \mathrm{e}-03)\end{array}$ & MA1 & $\begin{array}{l}0.5572 * * * \\
(9.567 \mathrm{e}-05)\end{array}$ & AR8 & $\begin{array}{l}0.0586^{* * *} \\
(0.0022)\end{array}$ \\
\hline AR9 & $\begin{array}{l}0.1827 * * * \\
(1.261 \mathrm{e}-03)\end{array}$ & MA2 & $\begin{array}{l}0.9847 * * * \\
(9.937 \mathrm{e}-05)\end{array}$ & AR9 & $\begin{array}{l}0.0047 \\
(0.0026)\end{array}$ \\
\hline Ar10 & $\begin{array}{l}0.1512 * * * \\
(7.569 \mathrm{e}-05)\end{array}$ & MA3 & $\begin{array}{l}0.2598 * * * \\
(1.016 \mathrm{e}-04)\end{array}$ & AR10 & $\begin{array}{l}0.1907 * * * \\
(0.0028)\end{array}$ \\
\hline AR11 & $\begin{array}{l}0.1025 * * * \\
(8.032 \mathrm{e}-05)\end{array}$ & MA4 & $\begin{array}{l}0.9287 * * * \\
(1.038 \mathrm{e}-04)\end{array}$ & AR11 & $\begin{array}{l}0.0952 * * * \\
(0.0024)\end{array}$ \\
\hline AR12 & $\begin{array}{l}0.3090 * * * \\
(5.710 \mathrm{e}-05)\end{array}$ & MA5 & $\begin{array}{l}0.6446 * * * \\
(1.062 \mathrm{e}-04)\end{array}$ & AR12 & $\begin{array}{l}0.0329 * * * \\
(0.0027)\end{array}$ \\
\hline MA1 & $\begin{array}{l}0.3453 * * * \\
(1.480 \mathrm{e}-04)\end{array}$ & MA6 & $\begin{array}{l}0.9127 * * * \\
(1.052 \mathrm{e}-04)\end{array}$ & MA1 & $\begin{array}{l}0.0952 * * * \\
(0.0035)\end{array}$ \\
\hline MA2 & $\begin{array}{l}0.0516 * * * \\
(1.790 \mathrm{e}-04)\end{array}$ & $\omega$ & $\begin{array}{l}0.0113 \\
(0.0241)\end{array}$ & MA2 & $\begin{array}{l}0.3289 * * * \\
(0.0030)\end{array}$ \\
\hline MA3 & $\begin{array}{l}0.3352 * * * \\
(1.866 \mathrm{e}-04)\end{array}$ & $\alpha$ & $\begin{array}{l}1.0000 \\
(1.9370)\end{array}$ & MA3 & $\begin{array}{l}0.2688 * * * \\
(0.0054)\end{array}$ \\
\hline MA4 & $\begin{array}{l}0.7582 * * * \\
(1.758 \mathrm{e}-04)\end{array}$ & $\beta$ & $\begin{array}{l}0.8467 * * * \\
(0.0614)\end{array}$ & MA4 & $\begin{array}{l}0.7845^{* * *} \\
(0.0039)\end{array}$ \\
\hline$\omega$ & $\begin{array}{l}6.161 \mathrm{e}-04 \\
(9.575 \mathrm{e}-04)\end{array}$ & $\gamma$ & $\begin{array}{l}0.9083 * * * \\
(0.0597)\end{array}$ & $\omega$ & $\begin{array}{l}0.0079 * * * \\
(0.0018)\end{array}$ \\
\hline$\alpha$ & $\begin{array}{l}1.0000 \\
(0.4920)\end{array}$ & $\gamma$ & $\begin{array}{l}2.1060 * * * \\
(0.2460)\end{array}$ & $\alpha$ & $\begin{array}{l}0.2970 * * * \\
(0.0259)\end{array}$ \\
\hline$\beta$ & $\begin{array}{l}0.5482 * \\
(0.1344)\end{array}$ & LM-test & 1.0000 & $\beta$ & $\begin{array}{l}0.6993 * * * \\
(0.0253)\end{array}$ \\
\hline$\gamma$ & $\begin{array}{l}0.8862 * * * \\
(0.0065)\end{array}$ & $\log L$ & 15.2619 & $\gamma$ & $\begin{array}{l}0.6626^{* * *} \\
(0.0138)\end{array}$ \\
\hline$v$ & $\begin{array}{l}2.7080 * * * \\
(0.3821)\end{array}$ & AIC & 0.0340 & $v$ & $\begin{array}{l}1.0000 * * * \\
(0.0428)\end{array}$ \\
\hline LM-test & 0.9841 & BIC & 0.3785 & LM-test & 0.4531 \\
\hline $\log \mathrm{L}$ & 65.4508 & & & $\log L$ & 0.0170 \\
\hline AIC & 0.5522 & & & AIC & 0.2611 \\
\hline BIC & 0.1503 & & & BIC & 0.6630 \\
\hline
\end{tabular}

Note: Signif. codes are as follows: $0 * * * 0.001 * * 0.01 * 0.050 .1$. The numbers in the parentheses are the standard deviations. 
Table 3 KS Test for Uniform and Box-Ljung Test for Autocorrelation

\begin{tabular}{llll}
\hline KS Test & & & \\
\hline & Statistic & P value & Hypothesis \\
\hline$u_{1, t}$ & 0.0976 & 0.0933 & 0 (acceptance) \\
$u_{2, t}$ & 0.0670 & 0.4650 & 0 (acceptance) \\
$u_{3, t}$ & 0.0652 & 0.5013 & 0 (acceptance) \\
\hline Box-Ljung Test & & & \\
\hline & Moments & X-squared & P-value \\
\hline$u_{1, t}$ & First moment & 1.7570 & 0.8816 \\
& Second moment & 4.1513 & 0.5278 \\
& Third moment & 0.9194 & 0.9688 \\
$u_{2, t}$ & Fourth moment & 2.5339 & 0.7714 \\
& First moment & 2.5915 & 0.7626 \\
& Second moment & 2.6553 & 0.7529 \\
& Third moment & 4.1255 & 0.5315 \\
$u_{3, t}$ & Fourth moment & 0.8972 & 0.9704 \\
& First moment & 1.9974 & 0.8495 \\
& Second moment & 5.1570 & 0.3970 \\
& Third moment & 2.5577 & 0.7678 \\
& Fourth moment & 2.0434 & 0.8431 \\
\hline
\end{tabular}

Note: $u_{1, t}=F_{\text {skt }}\left(x_{\text {sing }, t}\right), u_{2, t}=F_{\text {skt }}\left(x_{\text {malay }, t}\right)$, and $u_{3, t}=F_{\text {sged }}\left(x_{\text {thai }, t}\right)$

Singapore and Malaysia from China is not independent, and that the Survival Gumbel copula fits them very well. Thus, the Thailand inbound tourism from China may exert an influence on the inbound tourism demand of Singapore and Malaysia from China. In addition, both the best $C_{T M \mid S}$ and $C_{T S \mid M}$ are Frank copulas. The Kendall's tau of $C_{T M \mid S}$ and $C_{T S \mid M}$ are 0.1494 and 0.5062 , respectively. If we compare $C_{S, T}$ with $C_{S T \mid M}$, it can be clearly observed that Malaysia inbound tourism from China makes little difference to the inbound tourism from China to Singapore and Thailand, whereas Thailand and Malaysia inbound tourism from China are partly affected by Singapore inbound tourism from China, corresponding to $C_{T, M}$ and $C_{M T \mid S}$. 
Table 4 Results of Vine Copulas and Kendall's tau

\begin{tabular}{|c|c|c|c|c|c|}
\hline Copulas & parameters & tail dependence & Kendall'tau & AIC & BIC \\
\hline \multicolumn{6}{|l|}{ C-vine or D-vine } \\
\hline Survival Gumbel $\left(C_{T, M}\right)$ & $\begin{array}{l}1.2570 * * * \\
(0.0769)\end{array}$ & 0.2643 & 0.2045 & -14.5042 & -11.4228 \\
\hline $\operatorname{Frank}\left(C_{T, S}\right)$ & $\begin{array}{l}6.2800^{* * * *} \\
(0.6354)\end{array}$ & 0 & 0.5285 & -111.5832 & -108.5018 \\
\hline $\operatorname{Gaussian}\left(C_{S M \mid T}\right)$ & $\begin{array}{l}0.0454 \\
(0.0769)\end{array}$ & 0 & 0.0289 & 1.6484 & 4.7298 \\
\hline \multicolumn{6}{|l|}{ Other pair copulas } \\
\hline Survival Gumbel $\left(C_{S, M}\right)$ & $\begin{array}{l}1.1854 * * * \\
(0.0650)\end{array}$ & 0.2054 & 0.1564 & -8.5131 & -5.4316 \\
\hline $\operatorname{Frank}\left(C_{M T \mid S}\right)$ & $\begin{array}{l}1.3697 * * * \\
(0.4934)\end{array}$ & 0 & 0.1494 & -5.7991 & -2.7177 \\
\hline $\operatorname{Frank}\left(C_{S T \mid M}\right)$ & $\begin{array}{l}5.8502 * * * \\
(0.6311)\end{array}$ & 0 & 0.5062 & -100.4416 & -98.3602 \\
\hline Dynamic copulas & $\omega$ & $\alpha$ & $\beta$ & AIC & $\mathrm{BIC}$ \\
\hline $\operatorname{Frank}\left(C_{M T \mid S}\right)$ & $\begin{array}{l}16.3448 * * * \\
(0.4409)\end{array}$ & $\begin{array}{l}0.1852 * * * \\
(0.0032)\end{array}$ & $\begin{array}{l}95.1764 * * * \\
(2.2623)\end{array}$ & -1.4235 & 1.6578 \\
\hline $\operatorname{Frank}\left(C_{S T \mid M}\right)$ & $\begin{array}{l}101.060 * * * \\
(7.6314)\end{array}$ & $\begin{array}{l}0.4608 * * * \\
(0.0039)\end{array}$ & $\begin{array}{l}1828.80 * * * \\
(11.4990)\end{array}$ & -101.9672 & -98.8858 \\
\hline
\end{tabular}

Note: Signif. codes are as follows: $0 * * * 0.001 * * 0.01 * 0.050 .1$. The numbers in the parentheses are the standard deviations.

\subsection{Application of dynamic dependence structure}

Patton [11] proposed the time-varying copulas that include the Gaussian and symmetric Joe copulas. Manner [42], Wu [13], and Ng et al. [27] further researched the time-varying copulas. In our case, we follow our predecessors achievements to invent the time-varying Frank copula. The formula can be expressed as

$$
\theta_{t}=\Lambda\left(\omega+\alpha \theta_{t-1}+\beta\left(u_{i, t-1}-0.5\right)\left(u_{j, t-1}-0.5\right)\right)
$$

where $\Lambda(x)=\ln (x)$ is the logistic transformation, $0=<\alpha=<1$. The formula for Kendall's tau derived for the Frank copula is

$$
\tau=1-\frac{4}{\theta}+4 \frac{D_{1}(\theta)}{\theta} \text { where }_{1}(\theta)=\frac{1}{\theta} \int_{0}^{\theta} \frac{x}{\exp (x)-1} d x
$$


The second part of Table 4 reports the results of the time-varying copulas. In terms of AIC and BIC, the time-varying CST-M exhibits better explanatory ability than the static Frank copula, while it is the other way round for $C_{M T \mid S}$. We can see that the autoregressive parameter $\alpha$ in the time-varying Frank copula $C_{S T \mid M}$ equals to 0.4608 , implying a low degree of persistence pertaining to the dependence structure between Thailand and Singapore inbound tourism demand from China, given Malaysia inbound tourism demand from China. The dynamic Kendall's tau from the Frank copula $C_{S T \mid M}$ is illustrated in Figure 2, and we can see that the smallest value of Kendall's tau is approximately 0.36, while the greatest is about 0.54 , indicating that the nonlinear correlations are always shifting with time, and have seasonal volatility.

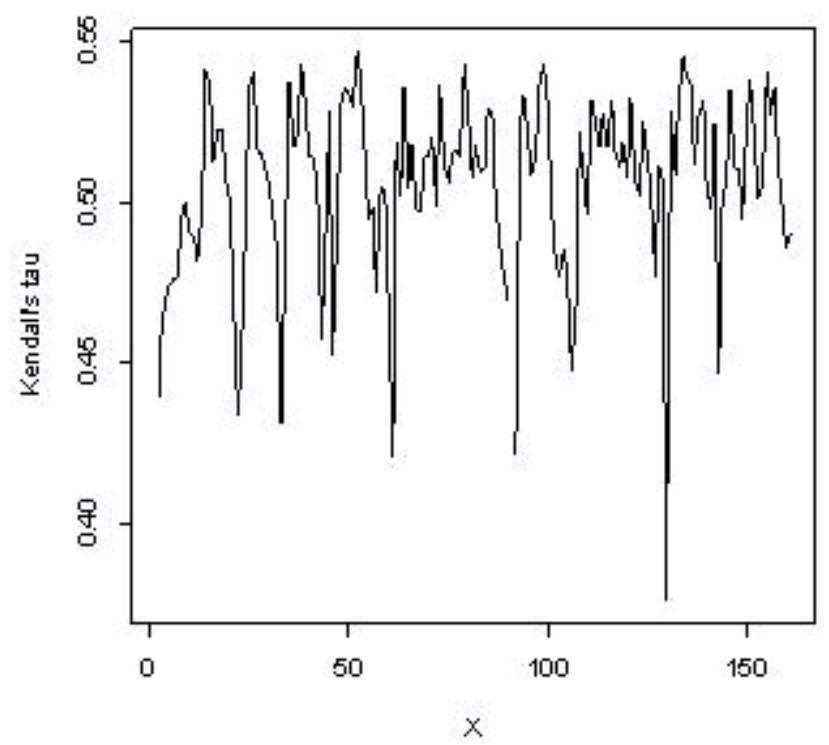

Fig. 2 Kendall's tau from the time-varying Frank copula $C_{S T \mid M}$. 


\section{Policy planning}

The empirical findings of this study reveal that there exists obvious volatility and interdependency in the Chinese tourist flow to the countries of SMT. Hence, tour operators and national tourism promotion authorities of SMT should collaborate closely in marketing and promoting joint tourism ventures and products.

As for Thailand and Singapore, the Chinese tourist flow to both these countries is highly correlated, especially in December, January, and February every year. In this case, the travel agents and airlines in Thailand and Singapore should come to a strong mutual understanding, cooperate to form a powerful alliance, and launch tourism packages through different routes. Given that the correlation gets reduced in May and June every year, it becomes more important that a series of high quality and low cost travel programs are launched for attracting tourists; as for Thailand and Malaysia, there exists a lower tail correlation in the Chinese tourist flow to these countries, which explains why a negative impact will shock their inbound tourism demand. Therefore, the tourism authorities of Thailand and Malaysia should enhance awareness of prevention, and jointly deploy some tourism program for stimulating the development of the tourism market; as for Singapore and Malaysia, the relevance of Malaysia and Singapore is similar to that of Malaysia and Thailand, and is also lower tail related, so the two countries should also implement similar measures toward meeting unexpected needs.

On the whole, among the three countries, Thailand plays a crucial role. The tourist population of China traveling to Thailand directly impacts the dependency of Singapore and Malaysia, since $C_{S M \mid T}$ indicates that Malaysia and Singapore are independent in the case of a known tourist flow of Thailand.

\section{Conclusions}

This paper examined the vine copula-ARMA-GARCH model based on past tourist arrivals from China which is a major tourist source market for SMT. This paper applied separately the logarithm differences of the monthly tourist arrivals to SMT from China. The empirical findings of this study indicate that ARMA-GARCH with assumed skewed student-t distribution for standardized residuals is the best-fitting model to explain the volatility of the tourist flow to Singapore and Malaysia from China, while ARMA-GARCH with assumed skewed-GED distribution for standardized residual is the appropriate model for analyzing the tourist flow to Thailand from China. In addition, various diagnostic cheeks were also used. We discuss how traditional tests for marginal distribution, using the Kolmogorov-Smirnov and BoxLjung tests, can be implemented to see if the underlying assumptions are satisfied. 
In addition, fifteen kinds of static copulas were used to analyze the dependence between the tourist flows to the SMT from China. Another point is that we applied the time-varying vine copulas that described the dynamic Kendall's tau. Finally, in the light of the empirical findings, we propose some constructive ideas and policy planning for the attention of the tourism authorities and travel agents.

\section{References}

1. Li, X., Lai, C., Harrill, R., Kline, S., Wang, L.: When east meets west: An exploratory study on Chinese outbound tourists travel expectations. Tourism Management 32, 741-749 (2011)

2. Lee, C.G.: The dynamic interactions between hotel room rates and international inbound tourists: Evidence from Singapore. International Journal of Hospitality Management 29, 758760 (2010)

3. Chang, C., Sriboonchitta, S., Wiboonpongse, A.: Modelling and forecasting tourism from East Asia to Thailand under temporal and spatial aggregation. Mathematics and Computers in Simulation 79, 1730-1744 (2009)

4. Liu, J., Sriboonchitta, S.: Analysis of Volatility and Dependence between the Tourist Arrivals from China to Thailand and Singapore: A Copula-based GARCH Approach. Uncertainty Analysis in Econometrics with Applications Advances in Intelligent Systems and Computing 200, 283-294. Springer, Heidelberg (2012)

5. Kim, S.S., Wong, K.F.: Effect of news shock on inbound tourist demand volatility in Korea. Journal of Travel Research 44(4), 457-466 (2006)

6. Song, H., Romilly, P., Liu, X.: An empirical study of outbound tourism demand in the U.K. Applied Economics 32(5), 611-624 (2000)

7. Chan, F., Lim, C., McAleer, M.: Modelling multivariate international tourism demand and volatility. Tourism Management 26, 459-471 (2005)

8. Hoti, S., McAleer, M., Shareef, R.: Modeling international tourism and country risk spillovers for Cyprus and Malta. Tourism Management 28(6), 1472-1484 (2007)

9. Seo, J.H., Park, S.Y., Yu, L.: The analysis of the relationships of Korean outbound tourism demand: Jeju Island and three international destinations. Tourism Management 30, 530-543 (2009)

10. Patton, A.J. : Modelling asymmetric exchange rate dependence. International Economics Review 47 (2), 527-556 (2006)

11. Jondeau, E., Rockinger, M.: The copula-GARCH model of conditional dependencies: an international stock market application. Journal of International Money and Finance 25, 827-853 (2006)

12. Lee, T., Long, X.: Copula-based multivariate GARCH model with uncorrelated dependent errors. Journal of Econometrics 150 (2), 207-218 (2009) 
13. Wu, C.C., Chung, H., Chang, Y.H.: The economic value of co-movement between oil price and exchange rate using copula-based GARCH models. Energy Economics 34(1), 270-282 (2012)

14. Wang, K., Chen, Y.H., Huang, S.W.: The dynamic dependence between the Chinese market and other international stock markets: a time-varying copula approach. International review of economics and finance 20 (4), 654-664 (2011)

15. Joe, H., Hu, T.: Multivariate distributions from mixtures of maxinfinitely divisible distributions. Journal of Multivariate Analysis 57 (2), 240-265 (1996)

16. Brechmann, E.C., Schepsmeier, U.: Modeling Dependence with C- and D-Vine Copulas: The R Package CDVine. Journal of Statistical Software 52(3), 1-27 (2013)

17. Bedford, T., Cooke, R.M.: Monte Carlo simulation of vine dependent random variables for applications in uncertainty analysis. In Proceedings of ESREL2001, Turin, Italy (2001)

18. Bedford, T., Cooke, R.M.: Vines-a new graphical model for dependent random variables. Annals of Statistics 30 (4), 1031-1068 (2002)

19. Min, A., Czado, C.: Bayesian inference for multivariate copulas using pair-copula constructions. Journal of Financial Econometrics 8 (4), 511-546 (2010)

20. Aas, K., Czado, C., Frigessi, A., Bakken, H.: Pair-copula construction of multiple dependence. Insurance: Mathematics and Economics 44, 182-198 (2009)

21. Czado, C.: Pair-Copula Constructions of Multivariate Copulas. Copula Theory and Its Applications. Lecture Notes in Statistics, Vol. 198, pp. 93-109. Springer, Heidelberg (2010)

22. Czado, C., Schepsmeier, U., Min, A.: Maximum likelihood estimation of mixed C-vines with application to exchange rates. Statistical Modelling 12, 229-255 (2012)

23. Bollerslev, T.: Generalized autoregressive conditional heteroskedasticity. Journal of Econometrics 31, 307-327 (1986)

24. Ling, S.: Self-weighted and local quasi-maximum likelihood estimators for ARMAGARCH/IGARCH models, Journal of Econometrics 140, 849-873 (2007)

25. Sklar, M.: Fonctions de repartition 'an dimensions et leurs marges. Publ. Inst. Statist. Univ. Paris 8, 229-231 (1959)

26. Manner, H., Reznikova, O.: A survey on time-varying copulas: Specification, simulations and application. Econometric Reviews 31(6), 654-687 (2012)

27. Ng, W.L.: Modeling duration clusters with dynamic copulas. Finance Research Letters 5, 96-103 (2008) 